\title{
Product customisation through postponement and CE tools integration in an aerospace company
}

\section{Cássio Dias Gonçalves*}

Brazilian Aeronautics Institute of Technology (ITA),

Av. Independência, 531, CEP 12031-000,

Jabuticabeiras, Taubaté, São Paulo, Brazil

E-mail: cdgoncal@yahoo.com.br

*Corresponding author

\section{Geilson Loureiro}

Integration and Testing Laboratory (LIT),

Brazilian Institute for Space Research (INPE),

Av. dos Astronautas 1758 Jd. da Granja,

CEP 12227-010, São José dos Campos,

São Paulo, Brazil

E-mail: geilson@lit.inpe.br

\section{Luís Gonzaga Trabasso}

Brazilian Aeronautics Institute of Technology (ITA),

Praça Marechal Eduardo Gomes,

50, Vila das Acácias, CEP 12228-900,

São José dos Campos, São Paulo, Brazil

E-mail: gonzaga@ita.br

\begin{abstract}
This paper aims to demonstrate a method to implement a product customisation strategy in an aerospace company through the integration between postponement and $\mathrm{CE}$ tools:

a determining the best time to make the main decisions related to postponement implementation, during the product development phase

b mapping the relationships among functional and physical product characteristics with the customer needs and even so guaranteeing the accomplishment with the programme budget

c identifying, during the product development phase, the optimal level of postponement that should be adopted.
\end{abstract}

Keywords: product customisation; postponement; concurrent engineering; mass customisation; aerospace industry.

Reference to this paper should be made as follows: Gonçalves, C.D., Loureiro, G. and Trabasso, L.G. (2011) 'Product customisation through postponement and CE tools integration in an aerospace company', Int. J. Mass Customisation, Vol. 4, Nos. 1/2, pp.1-21. 
Biographical notes: Cássio Dias Gonçalves graduated in Mechanical Engineering from UNESP (the University of São Paulo State), Guaratinguetá, Brazil, in 2000. He finished his MSc on Aeronautics and Mechanical Engineering at ITA (the Brazilian Technological Institute of Aeronautics, www.ita.br) in 2008. He worked as Process Development Engineer at EMBRAER from 2001 to 2007, developing manufacturing processes, systems and methods, also taking part directly in the product design. Since 2007, he has been working as Engineering and Planning Manager at an aircraft MRO (maintenance, repair and overhaul) company. Accordingly, in his scientific publications, the most often used terms are: postponement, PERT/CPM, PLM, concurrent engineering, mass customisation.

Geilson Loureiro is a Professor of Systems Engineering at ITA (the Brazilian Technological Institute of Aeronautics, www.ita.br) and at INPE (the Brazilian Institute for Space Research). He obtained his $\mathrm{PhD}$ at Loughborough University, England in 1999, working in collaboration with Ford Motor Company. In 2004 and 2005, he worked as a Post Doc Associate at MIT (Massachusetts Institute of Technology) on the concepts of exploration and refinement project for NASA. He has been working for INPE since January 1988, on many stages of satellite life cycle including: manufacturing, integration and testing.

Luís Gonzaga Trabasso graduated in Mechanical Engineering from UNESP (the University of São Paulo State), Brazil, in 1982. He finished his MSc on Space Engineering and Technology at INPE (the Brazilian Institute for Space Research) in 1985. He obtained his PhD thesis on Mechanical Engineering Loughborough University in 1991. Currently, he is an Associate Professor at the Mechanical-Aeronautics Engineering Department of the ITA (the Brazilian Technological Institute of Aeronautics, www.ita.br). His research fields are concurrent engineering and mechatronics, with emphasis on industrial automation and robotics.

\section{Introduction}

The current economic scenario is characterised by uncertainty and high competition level. As a consequence of the first factor, companies are facing difficulties to do the demand forecast. In the aerospace market, a bad demand forecast means changes in the schedule of customer orders and aircraft's reconfiguration in the assembly line (Iyer et al., 2003), in other words, money lost. The high competition level in the market creates a more stringent customer profile, where they have specific desires, asking for more customised products, shorter delivery times and lower prices (Ame Info., 2004). However, if the company offers customised products, the cost of reconfigurations increases. Figure 1 provides an overview of this scenario.

According to this context, to remain competitive in the global market, the company must avoid the occurrence of aircraft's reconfigurations, adopting a strategy to make its customisation process more flexible, postponing the product configuration to as late as possible in the production phase (Cunha, 2002). This reduces production costs, improves customer service as delivery time is shortened and increases the overall programme profit.

This strategy is named postponement: an operational concept that consists of delaying the product configuration until the actual customer demand is known (Sampaio et al., 2003). 
This is not a recent concept. In the literature, this concept was created by Wroe Alderson in 1950 (Ma et al., 2002). Only a few studies were developed between 1950 and 1990, result of weak academic efforts in the field in this period.

The broadcasting of the Benetton and HP success cases in the 1990's reinforced the research in this field (Bullock, 2002).

Figure 1 Relationships among market, company and customer

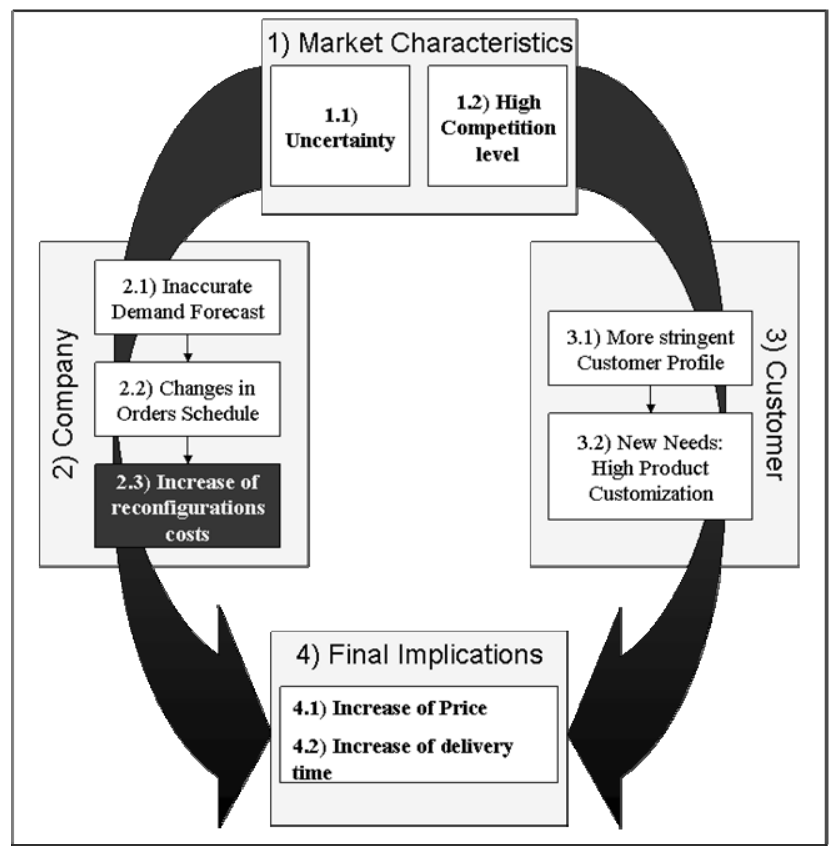

Nowadays, there is a hot spot in high-tech and mass production industries (Bullock, 2002), mainly because the inventory costs, related to obsolescence and quantity. In this case, the works usually propose mathematical models to evaluate and indicate the inventory levels by the demand forecast functions (Aviv and Federgruen, 2001).

In general, most works propose the increase of the customer service; however, just a few evaluate the impacts on the customer needs by the process and product changes (Tseng and Jiao, 1998).

Rarely authors mention the relationship between postponement and concurrent engineering; however the integration between these two subjects is an important requirement for the implementation of this strategy. The strategy addresses the following issues:

- integration among different technical areas such as product engineering, process engineering, logistics and sales department

- main factors that affect the customer needs (Prats and Patterson, 2003):

1 the aircraft's operational cost

2 the number of optional items offered to the customer

3 the aircraft's delivery time. 
- some factors affecting costs:

1 inventory levels may change (Lembke and Bassok, 2004; Graman, 2002)

2 high value added items may be installed earlier

3 design solutions may affect the product cost.

Considering these characteristics, a company may create many alternatives of product design and manufacturing processes to implement postponement (SM Thacker and Associates, 2000), for example: applying design modularisation (Bullock, 2002); constraining the number of optional items (Waller et al., 2000); employing buffers for the component bottlenecks or reorganising manufacturing processes to install the parts that configure the product as late as possible.

The work described herein has identified some concurrent engineering tools that may help to make decisions at the right time and choose the best product alternative. These are: design to cost (DTC), quality function deployment (QFD), decision trees (Beckman and Neto, 2000; Raiffa, 1970), multi-criteria systems, design structure matrix (DSM) and critical path method (CPM). This paper proposes a postponement method that makes an adapted and systematic use of some of those tools, provides an example of application and discusses the effect of such method on cost reduction and customer satisfaction.

\section{Proposed method}

As can be seen in Figure 1, the impacts caused on companies and customers by the new market scenario generate an increase in product price and delivery time, both are undesirable results. In this context, to improve these results, nothing can be done to change the market characteristics neither the customer profile. Thus the unique way to reduce the product price and delivery time is to change the company processes, more specifically the aircraft's customisation process (see Box 2.3 of Figure 1). This paper aims to demonstrate a method that integrates manufacturing postponement and concurrent engineering tools to develop a product customisation strategy in this company.

The method to develop this customisation strategy consists of two parts: the first part is related to the planning of the decisions that must be made to postpone the product customisation during its manufacturing phase. The second part consists of a systematic procedure to support these decisions made, through the choice of the best design alternative, which presents lower cost, while keeping focus on customer needs. Both parts shall occur during the product development phases.

\subsection{First part of the method: planning of the decisions that must be made to postpone the product customisation during its production phase}

\subsubsection{Identification in the product and its manufacturing process what impacts customisation most, i.e., the critical items - CPM (Darci, 2004)}

The CPM will be used to develop the precedence network of the aircraft manufacturing and assembly processes (Souza, 2000). Then it is possible to identify the most critical items that contribute to increase the customisation cycle time. Through this precedence network, the level of postponement (as depicted in Figure 2) is calculated based on: 
Ccustom $=\mathrm{Ccm}+\mathrm{Cca}$

where

Ccustom aircraft customisation cycle time (days)

$\mathrm{Ccm} \quad$ customisation cycle time for manufacturing (days)

Cca customisation cycle time for assembly (days)

Figure 2 Aircraft's customisation cycle time

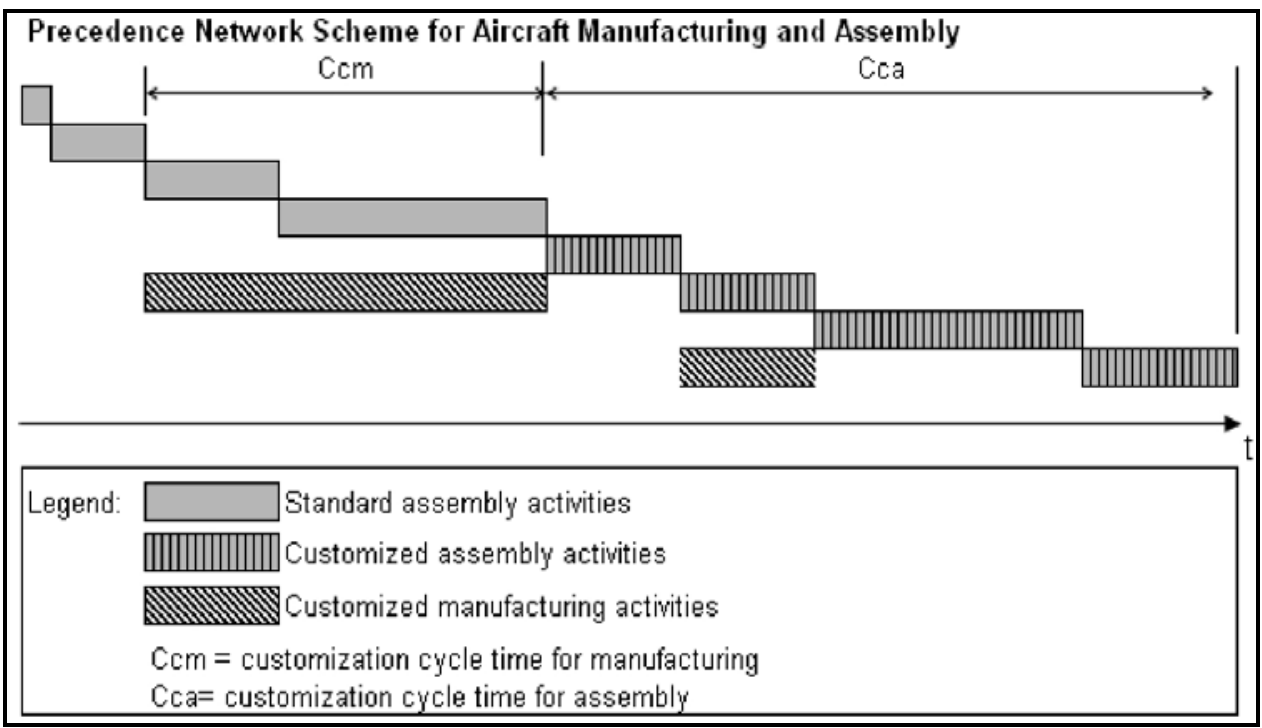

\subsubsection{For the critical items, identify the opportunities of design alternatives that should be considered in order to postpone the product customisation during its manufacturing phase}

Once the most critical items that contribute to increase the customisation cycle time are identified, some questions and decisions are formulated about the design and manufacturing of the critical items to promote this cycle time reduction. Depending on answers for these questions and decisions, different aircraft and its manufacturing process design alternatives will be created.

\subsubsection{Schedule questions to be answered and decisions to be made (DSM) within the product development process (CPM).}

It is needed to consider three kinds of elements in a decision making process: milestones, decisions and questions, and they relate to each other as following (NASA, 2005):

- the milestones accomplishments depend on the decisions made

- decisions depend on the answer of some questions

- also, milestones may depend on other milestones, decisions may depend on other decisions and questions may affect each other. 
The numerical DSM activity-based tool (MIT and UIUC DSM, 2003) can be used to create the relationships among these elements and rank them according to a priority criterion. In this work, a DSM adaptation is required to define each activity time length, instead of priority relationships (Hoffmeister, 2003). The CPM was selected to determine the best time each element takes place in a new aircraft development project (Peralta, 2002). CPM can be used because the statistical variance of the activity durations is insignificant (Darci, 2004). The primavera project planner (P3) (1997) has been used to implement CPM. The Numerical-DSM is used and its results are input to P3 to generate the project activities programming (Peralta and Tubino, 2003). After this precedence network is calculated, it is related with a product development plan to determine the ideal schedule to answer each question, to make the decisions and to accomplish the milestones, without affecting the programme end date.

\subsection{Second part of the method: to support the decision making process, taking into consideration not only the financial factors, but also the customer satisfaction}

The QFD (Lee and Kusiak, 2001) and DTC (Michaels and Wood, 1989) tools will help to determine the best aircraft design and manufacturing alternative according to cost constraints and customer needs. Where, through QFD, the customer needs will be related with the company's engineering and manufacturing requirements. The QFD tool also will weigh the relationship between these requirements and the aircraft's parts and manufacturing processes. The DTC technique will be used to compare the target costs with the estimated costs, pointing which aircraft part or process must be redesigned to attend the target cost. The essence of DTC is to make design converge on cost, instead of allowing cost to converge on design. DTC is a management concept that mandates cost success in terms of producing products or systems at a cost deemed to be affordable from the customer's perspective (Vitaliano, 1994).

Total probability theorem (Beckman and Neto, 2000) helps to define the optional kits for the aircraft.

\section{Case study}

This section aims to demonstrate a practical example of the proposed method application in an aerospace company. The goal is to define the best aircraft's design that promote the optimal level of postponement according the programme financial constrains and attending the customer needs.

\subsection{First part: decision making process planning}

\subsubsection{Identification in the product and its manufacturing process what impacts customisation most, i.e., the critical items}

Applying CPM to the aircraft manufacturing and assembly process, allows the definition of the most critical aircraft components, which increases the value of Ccustom (Pinedo, 2002). They are: 
- $\quad$ main hardness

- furnishings (interiors)

- electronics equipments (such as avionics, entertainment options).

\subsubsection{For the critical items, identify the opportunities of design alternatives that should be considered in order to postpone the product customisation during its manufacturing phase}

After the identification of the critical items, some questions and decisions are formulated about how the design and manufacturing of these components can contribute to reduce Ccustom. The answers to these questions and the decisions made define the level of postponement to be used in order to produce the aircraft. Table 1 lists those questions and decisions.

Table 1 Questions and decisions list

\begin{tabular}{|c|c|c|}
\hline Code & Description & Technical area \\
\hline D1 & \multicolumn{2}{|c|}{ Hardness: standard; customised; standard in cockpit and customised in fuselage } \\
\hline Q1 & $\begin{array}{l}\text { Is it technically possible? } \\
\text { (weight, manufacturing) }\end{array}$ & System engineering, weight, manufacture \\
\hline Q2 & Is it profitable? (trade-off) & Process engineering and supply \\
\hline Q3 & Does the customisation cycle time reduce? & Process engineering \\
\hline Q4 & $\begin{array}{l}\text { Are the customer needs affected? } \\
\text { (positive, negative, how much?) }\end{array}$ & Market and sales department \\
\hline Q5 & Is the fabrication lead time so far? & Process engineering and supply \\
\hline$D 2$ & \multicolumn{2}{|c|}{ Interiors: standard; customised; standard cockpit and customised PAX cabin } \\
\hline Q1 & $\begin{array}{l}\text { Is it technically possible? } \\
\text { (weight, manufacturing) }\end{array}$ & System engineering, weight, manufacture \\
\hline Q2 & Is it profitable? (trade-off) & Process engineering and supply \\
\hline Q3 & Do the customisation cycle time reduce? & Process engineering \\
\hline Q4 & $\begin{array}{l}\text { Is the customer needs affected? } \\
\text { (positive, negative, how much?) }\end{array}$ & Market and sales department \\
\hline Q5 & Is the fabrication lead time so far? & Process eng and supply \\
\hline D3 & \multicolumn{2}{|c|}{ Optional items list: constrained or not constrained } \\
\hline Q6 & How many optional items? & System eng and market department \\
\hline Q7 & Which optional items will be offered? & System eng and market department \\
\hline Q8 & $\begin{array}{l}\text { How to determine? (total probability } \\
\text { theorem) }\end{array}$ & Process engineering and market \\
\hline Q9 & $\begin{array}{l}\text { Are the customer needs affected? } \\
\text { (positive, negative, how much?) }\end{array}$ & Market department \\
\hline Q10 & Will the kits be created? & Process engineering and market \\
\hline D4 & Production buffers: to use or not? & \\
\hline Q5 & Is the fabrication lead time so far? & Process engineering \\
\hline Q11 & Is it profitable? (trade-off) & Process engineering \\
\hline
\end{tabular}




\subsubsection{Schedule questions to be answered and decisions to be made within the product development process}

The DSM tool was used to determine the relationships among questions and decisions. The first configuration of DSM elements generated a lot of interactions that usually increase cycle time and project cost. To optimise the DSM elements sequence, the partitioning algorithm (MIT and UIUC DSM, 2003) has been used. The resulting numerical DSM, with activity durations (in weeks) in the matrix main diagonal, is presented in Figure 3.

Figure 3 Final DSM after partition algorithm applying

\begin{tabular}{|c|c|c|c|c|c|c|c|c|c|c|c|c|c|c|c|}
\hline & 01 & 02 & 03 & 05 & 08 & 04 & 06 & 07 & 09 & 010 & 011 & D1 & D2 & D3 & D4 \\
\hline 01 & 10 & & & & & & & & & & & & & & \\
\hline 02 & & 5 & & & & & & & & & & & & & \\
\hline 03 & & & 4 & & & & & & & & & & & & \\
\hline 05 & & & & 6 & & & & & & & & & & & \\
\hline 08 & & & & & 7 & & & & & & & & & & \\
\hline 04 & & & $\mathrm{X}$ & & & 8 & & & & & & & & & \\
\hline 06 & & & & & $\mathrm{X}$ & & 10 & & & & & & & & \\
\hline 07 & & & & & & & $\mathrm{X}$ & 7 & & & & & & & \\
\hline 09 & & & & & $\mathrm{X}$ & & $\mathrm{X}$ & $\mathrm{X}$ & 5 & $\mathrm{X}$ & & & & & \\
\hline 010 & & & & & $\mathrm{X}$ & & $\mathrm{X}$ & $\mathrm{X}$ & $\mathrm{X}$ & 2 & & & & & \\
\hline 011 & & & & & $\mathrm{X}$ & & $\mathrm{X}$ & $\mathrm{X}$ & & & 6 & & & & \\
\hline D1 & $\mathrm{X}$ & $\mathrm{X}$ & $\mathrm{X}$ & $\mathrm{X}$ & & $\mathrm{X}$ & & & & & & 8 & & & \\
\hline D2 & $\mathrm{X}$ & $\mathrm{X}$ & $\mathrm{X}$ & $\mathrm{X}$ & & $\mathrm{X}$ & & & & & & & 4 & & \\
\hline D3 & & & & & $\mathrm{X}$ & & $\mathrm{X}$ & $\mathrm{X}$ & $\mathrm{X}$ & $\mathrm{X}$ & & & & 1 & \\
\hline D4 & $\mathrm{X}$ & & & $\mathrm{X}$ & & & $\mathrm{X}$ & $\mathrm{X}$ & & $\mathrm{X}$ & $\mathrm{X}$ & $\mathrm{X}$ & $\mathrm{X}$ & $\mathrm{X}$ & 4 \\
\hline
\end{tabular}

Figure 4 Network for questions, decisions and product development (see online version for colours)

\begin{tabular}{|c|c|c|}
\hline $\begin{array}{l}\text { Activity } \\
\text { ID }\end{array}$ & $\begin{array}{c}\text { Activity } \\
\text { Description }\end{array}$ & \\
\hline \multicolumn{3}{|c|}{ Product Development Schedule } \\
\hline 0010 & Conceptual Phase & 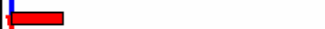 \\
\hline 0030 & Pre-Design Phase & \\
\hline 0040 & Joint Definition Preparation & \\
\hline 0050 & Joint Definition Phase & \\
\hline 0060 & Detailed Design & \\
\hline 0070 & Manufacturing & \\
\hline 0090 & First Flight & \\
\hline 0100 & Tests and Certification & \\
\hline 0130 & First Delivery & \\
\hline \multicolumn{2}{|c|}{ Questions:Decisions Network about Postponement } & \\
\hline Q3 & Does the customization cycle time reduce? & 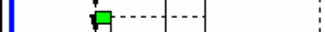 \\
\hline Q2 & Is it profitable? (Trade-off) & … \\
\hline Q8 & How to determine? (Total Probability Teorem) & … \\
\hline Q4 & is the customer affected? & $\square$ \\
\hline Q5 & How far is the fabrication lead time? & 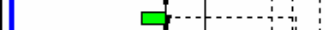 \\
\hline Q1 & Is technically possible? (weight, fabr, assy) & \\
\hline $\mathrm{D} 2$ & Interior will be: std; custom; ckpt stdipax cust & $\left(\begin{array}{ccc}1 \\
-1\end{array}\right.$ \\
\hline D1 & Hardness will be: Std; custom; ckpt stdifus cust & ש \\
\hline Q6 & How many optional iterns? & ב \\
\hline Q7 & Which optional items? & G. \\
\hline Q10 & Is it interesting to make Kits? & pit \\
\hline Q9 & Is the customer affected? & $\theta$ \\
\hline Q11 & Is it profitable? (Trade-off) & ㄴ. \\
\hline D3 & Is the number of optional items restricted? & \\
\hline D4 & Mill buffers be used? & 穴 \\
\hline MLLESTONE & Determine $\mathrm{Ccf}+\mathrm{Ccm}$ & 8 \\
\hline
\end{tabular}


After that, the DSM data is transferred to the P3 software, to calculate the precedence network and incorporate it into the product development plan. The best time for the questions and postponement decisions to happen is, therefore, determined.

Figure 4 shows the Gantt chart for the questions, decisions and the product development phases. Figure 4 does not present numerical values to preserve the company's confidential information.

\subsection{Second part of the method: to support the decision making process, taking into consideration not only the financial factors, but also the customer satisfaction}

Combining the options of decisions (listed in Table 1), a lot of design alternatives could be generated for the product and its manufacturing process. This study evaluates only two design alternatives. Basically, the set of decisions made for Alternative 1 does not contribute to postponement usage. On the other hand, the set of decisions made for Alternative 2 enable the postponement utilisation to produce an aircraft. The alternatives characteristics are shown in Table 2.

Table 2 Characteristics of product and process design alternatives

\begin{tabular}{|c|c|}
\hline Alternative 1 & Alternative 2 \\
\hline Customised hardness & $\begin{array}{l}\text { Standard hardness in cockpit and installed during } \\
\text { pre-equipage phase and customised in the fuselage } \\
\text { installed during the final assembly phase }\end{array}$ \\
\hline $\begin{array}{l}\text { Structural customisation during the } \\
\text { Structural Complementation Phase } \\
\text { (best time technically) }\end{array}$ & Standard fuselage structure \\
\hline Optional items limits unconstrained & Offered four kits of optional items \\
\hline No optional items stock & Optional items stocked \\
\hline $\begin{array}{l}\text { Customised interior and installed } \\
\text { during Final Assembly Phase }\end{array}$ & Stock for four kinds of hardness \\
\hline No interior items stock & $\begin{array}{l}\text { Standard interior in cockpit and customised in PAX } \\
\text { cabin (less optional items => reduced stock) } \\
\text { pre-equipage of forward fuselage (to facilitate access to } \\
\text { cockpit and to reduce customisation cycle time) }\end{array}$ \\
\hline
\end{tabular}

CPM was used also to determine the customisation cycle time. According to the precedence network of aircraft manufacturing, related to Alternative 1 and equation (1), the value of Ccustom 1 is:

$$
\begin{aligned}
& \text { Cca }=\text { Cca } 1[\text { days }] \\
& \text { Cca }=\text { Cca } 1[\text { days }] \\
& \text { Ccustom } 1=(\text { Ccm } 1+\text { Cca } 1)
\end{aligned}
$$

Alternative 1 does not adopt any kind of production buffers to the optional items, then the manufacturing lead times are included in the customisation cycle time, significantly increasing it.

According to the precedence network of aircraft manufacturing, related to Alternative 2 and equation (1), the value of Ccustom 2 is: 


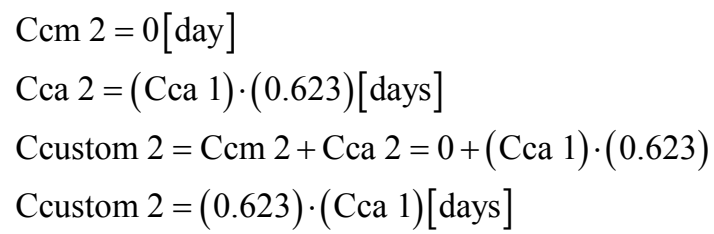

Alternative 2 proposes to offer optional kits to customer, as in the automotive industry. It was applied the Total Probability Theorem to determine the number of kits and its compositions (Beckman and Neto, 2000).

$$
P(B) \sum_{i=1}^{n} P(A i) \times P(B / A i)
$$

It was considered a list with thirteen optional items to be offered to the customers. The optional items were named (B1, B2, .., B13).

Other consideration was that the global market is divided in five regions, named (A1, A2, .., A5).

Thus, for each optional item, it was possible to estimate the conditional probabilities, according to Table 3 .

Table 3 Conditional probabilities of the optional items

\begin{tabular}{lll}
\hline Region & $B i$ & $\overline{B i}$ \\
\hline A1 & $P(B i / A 1)$ & $P(\overline{B i} / A 1)$ \\
A2 & $P(B i / A 2)$ & $P(\overline{B i} / A 2)$ \\
A3 & $P(B i / A 3)$ & $P(\overline{B i} / A 3)$ \\
A4 & $P(B i / A 4)$ & $P(\overline{B i} / A 4)$ \\
A5 & $P(B i / A 5)$ & $P(\overline{B i} / A 5)$ \\
\hline
\end{tabular}

Once the conditional probabilities were estimated, it was possible to build the bi-dimensional distribution tables for each optional item as shown in Table 4.

Table 4 Bi-dimensional distribution of probabilities

\begin{tabular}{lccc}
\hline Region & $B i$ & $\overline{B i}$ & Total \\
\hline A1 & $P(A 1 \cap B i)$ & $P(A 1 \cap \overline{B i})$ & $P(A 1)$ \\
A2 & $P(A 2 \cap B i)$ & $P(A 2 \cap \overline{B i})$ & $P(A 2)$ \\
A3 & $P(A 2 \cap B i)$ & $P(A 2 \cap \overline{B i})$ & $P(A 3)$ \\
A4 & $P(A 2 \cap B i)$ & $P(A 2 \cap \overline{B i})$ & $P(A 4)$ \\
A5 & $P(A 2 \cap B i)$ & $P(A 2 \cap \overline{B i})$ & $P(A 5)$ \\
Total & $P(B)$ & $P(\overline{B i})$ & 1 \\
\hline
\end{tabular}


Through the bi-dimensional distribution of probabilities, the unconditional probabilities of the optional items could be calculated as filed in Table 5 .

Table 5 Unconditional probabilities of the optional items

\begin{tabular}{lccccccccccccc}
\hline Optional items & $B 1$ & $B 2$ & $B 3$ & $B 4$ & $B 5$ & $B 6$ & $B 7$ & $B 8$ & $B 9$ & $B 10$ & $B 11$ & $B 12$ & $B 13$ \\
\hline $\begin{array}{l}\text { Probability of a } \\
\begin{array}{l}\text { lustomer to } \\
\text { choose the item } \\
(\%)\end{array}\end{array}$ & 85 & 11 & 5 & 12 & 0 & 50 & 11 & 5 & 6 & 10 & 8 & 79 & 13 \\
\hline
\end{tabular}

Combining the optional items in assembly kits with three items, it was possible to identify the four combinations most demanded by the global market: B1B6B12, $\mathrm{B} 1 \mathrm{~B} 12 \mathrm{~B} 13, \mathrm{~B} 6 \mathrm{~B} 12 \mathrm{~B} 13$ and B1B6B13. Due to the creation of four kinds of kits, it is necessary to keep four kinds of hardness in stock.

The best alternative, considering the programme cost constraints and customer needs, will be identified through techniques such as QFD and DTC.

For each alternative will be generated three matrices in the following order: first QFD matrix, second QFD matrix and DTC matrix. These matrices are interrelated as can be observed in Figure 3: the first QFD matrix relates the aircraft design and manufacturing requirements (system requirements) with the customer needs; the second QFD matrix, the design and manufacturing characteristics of the critical components (parts characteristics), with the system requirements. Finally, the DTC matrix helps to make the system requirements cost estimation from parts characteristics. Then, this estimated cost is compared with the programme target cost, weighted according to how customer values their needs accomplishments.

Figure 5 QFD and DTC matrices scheme

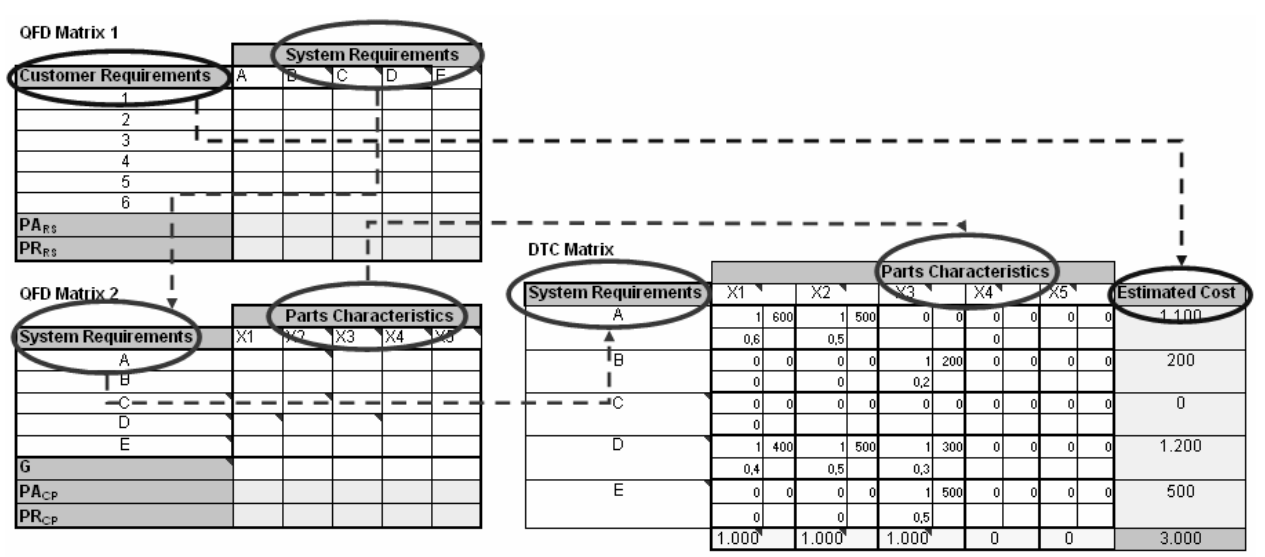

Follow the set of matrices for Alternative 1 (Tables 6 to 8) and Alternative 2 (Tables 9 to 11 ). 
Table 6 QFD matrix 1 for alternative 1

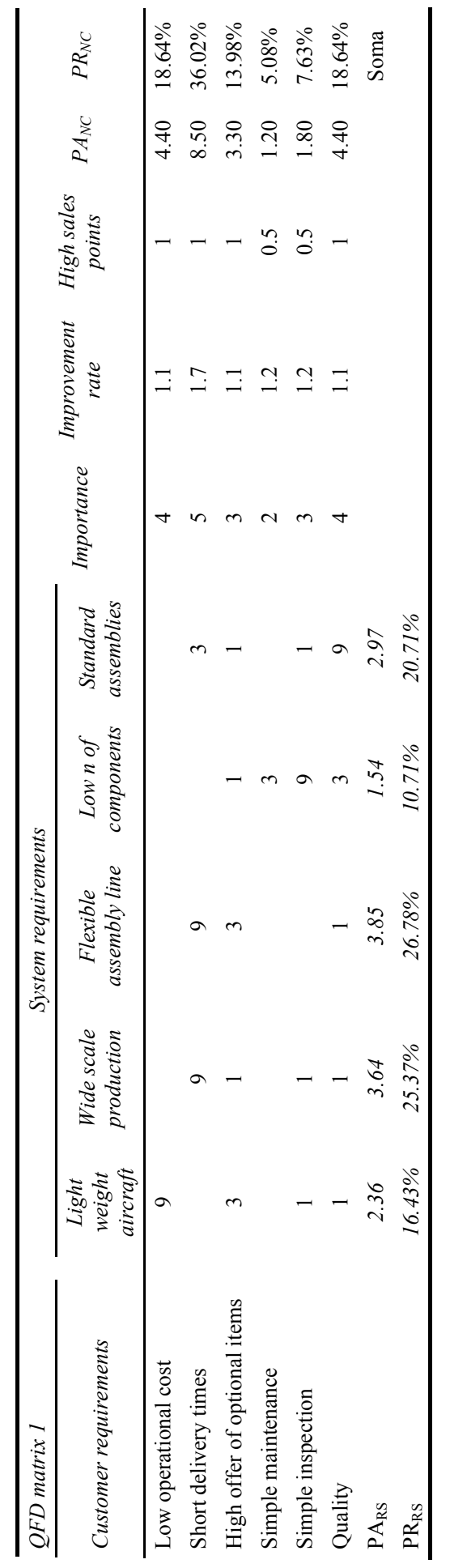


Table $7 \quad$ QFD matrix 2 for alternative 1

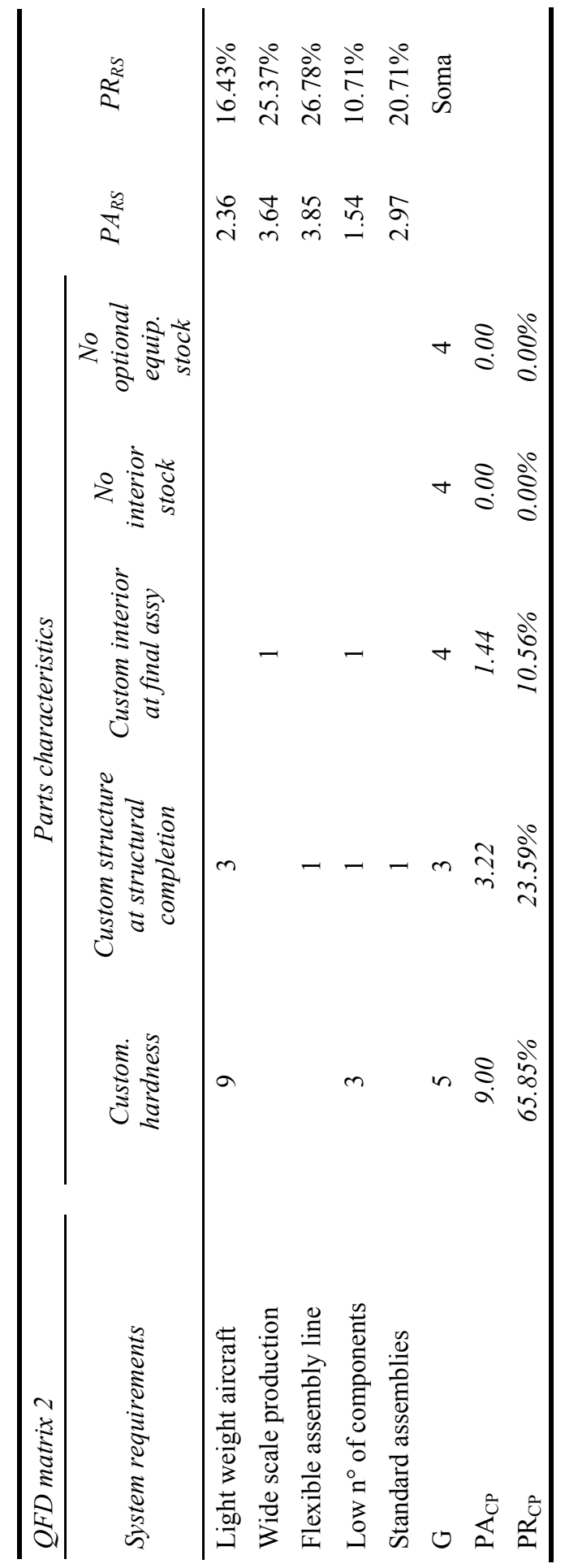


14 C.D. Gonçalves et al.

Table 8 DTC matrix for alternative 1

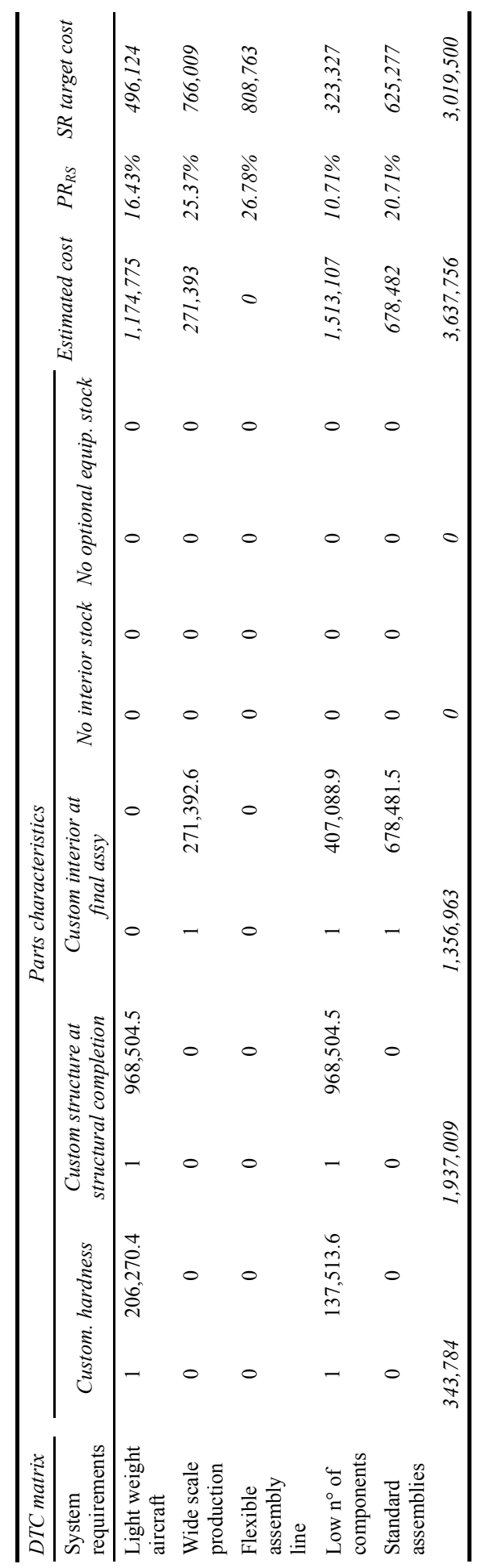


Table 9 QFD matrix 1 for alternative 2

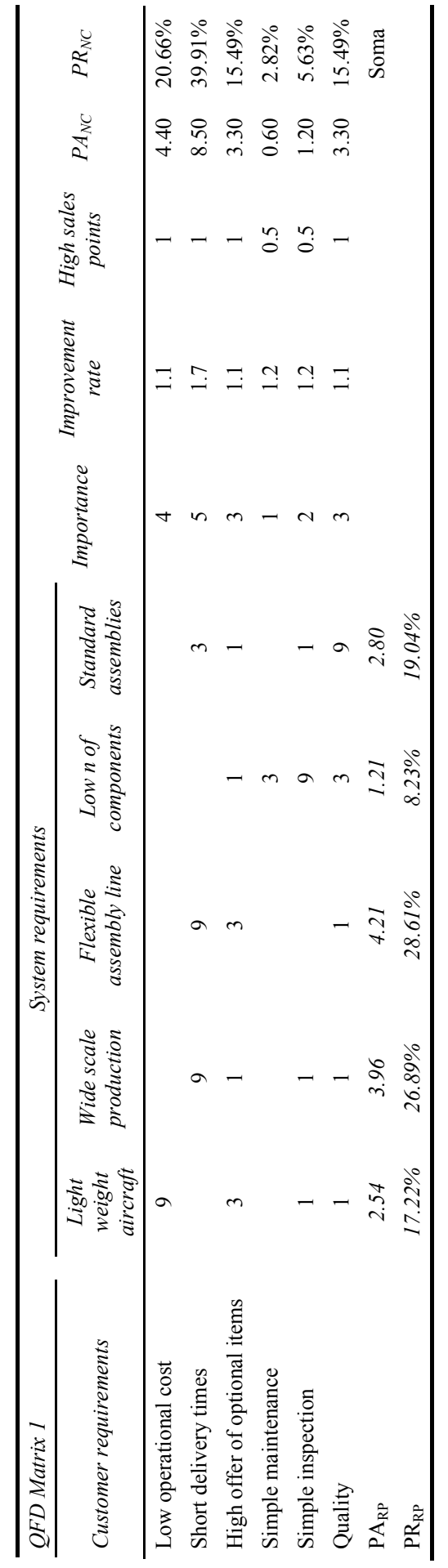


16 C.D. Gonçalves et al.

Table 10 QFD Matrix 2 for Alternative 2

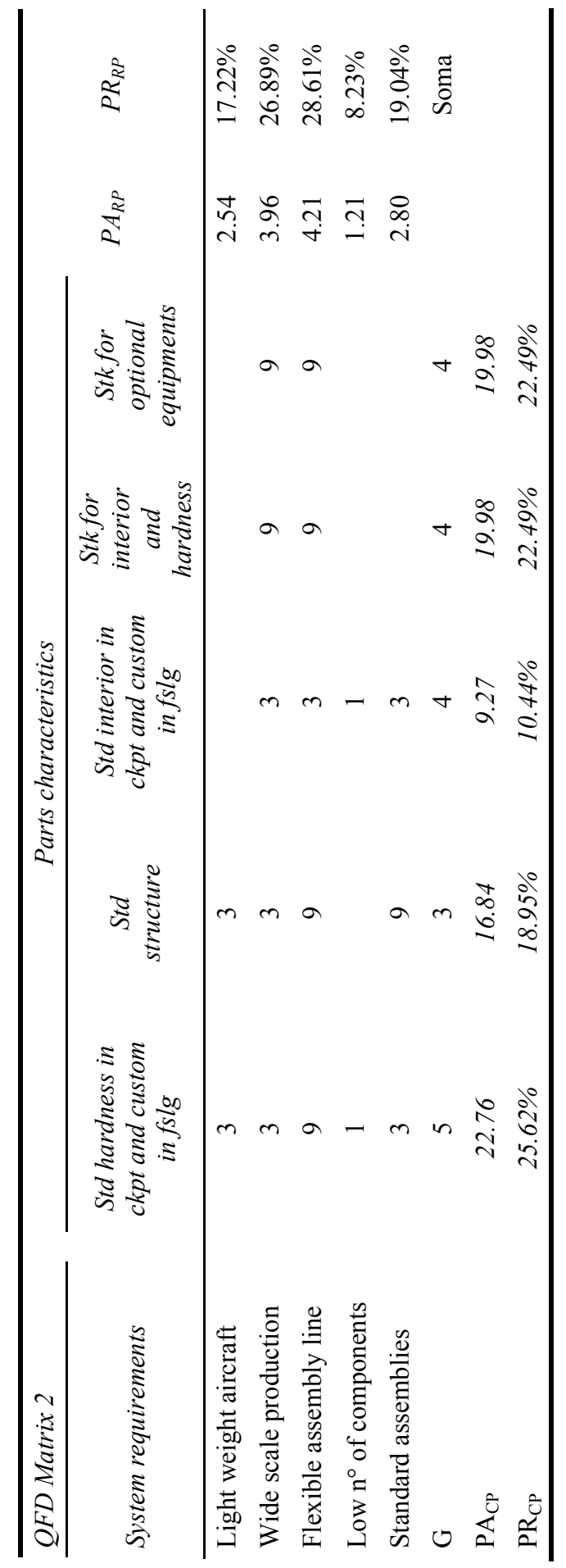


Table 11 DTC Matrix for Alternative 2

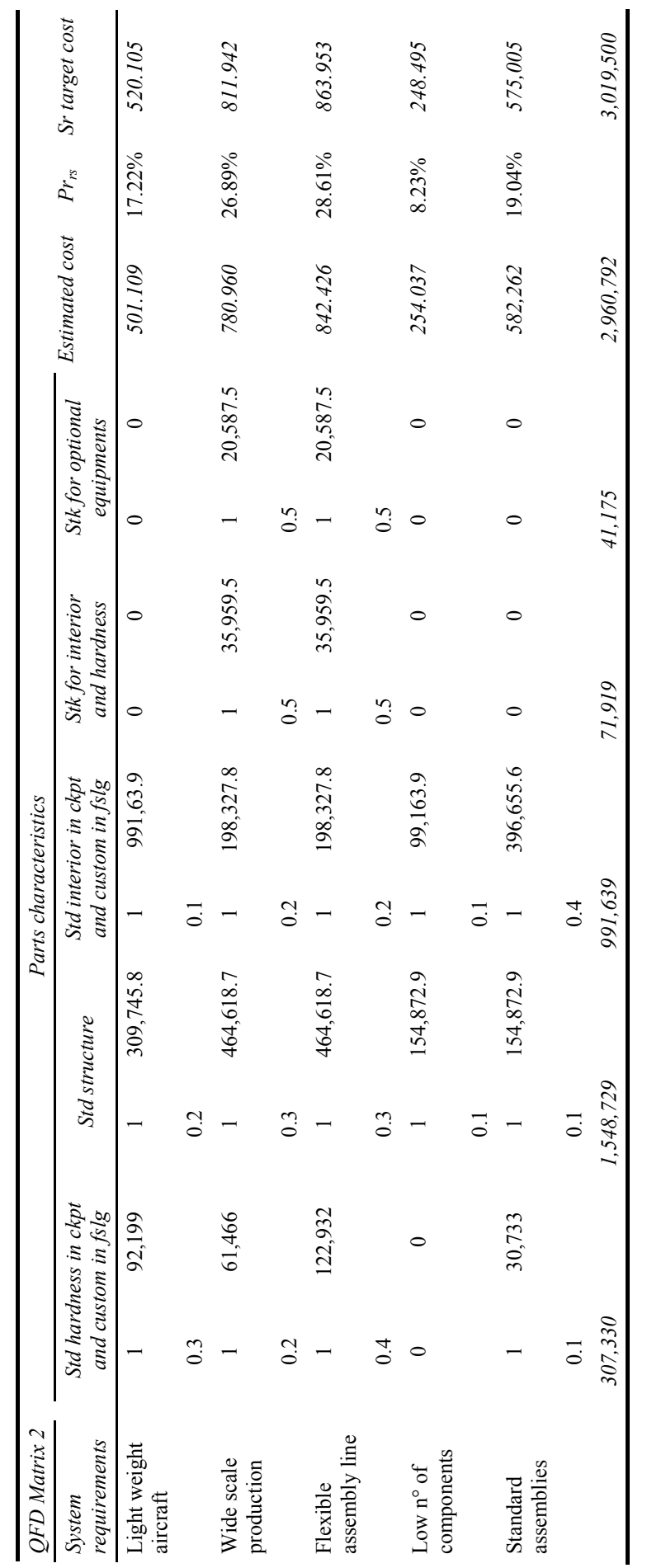


Figures 6 and 7 depict the comparison between the target and estimate costs for design Alternatives 1 and 2, respectively.

Figure 6 Comparison between the target cost distribution and the estimated cost distribution for design Alternative 1 (see online version for colours)

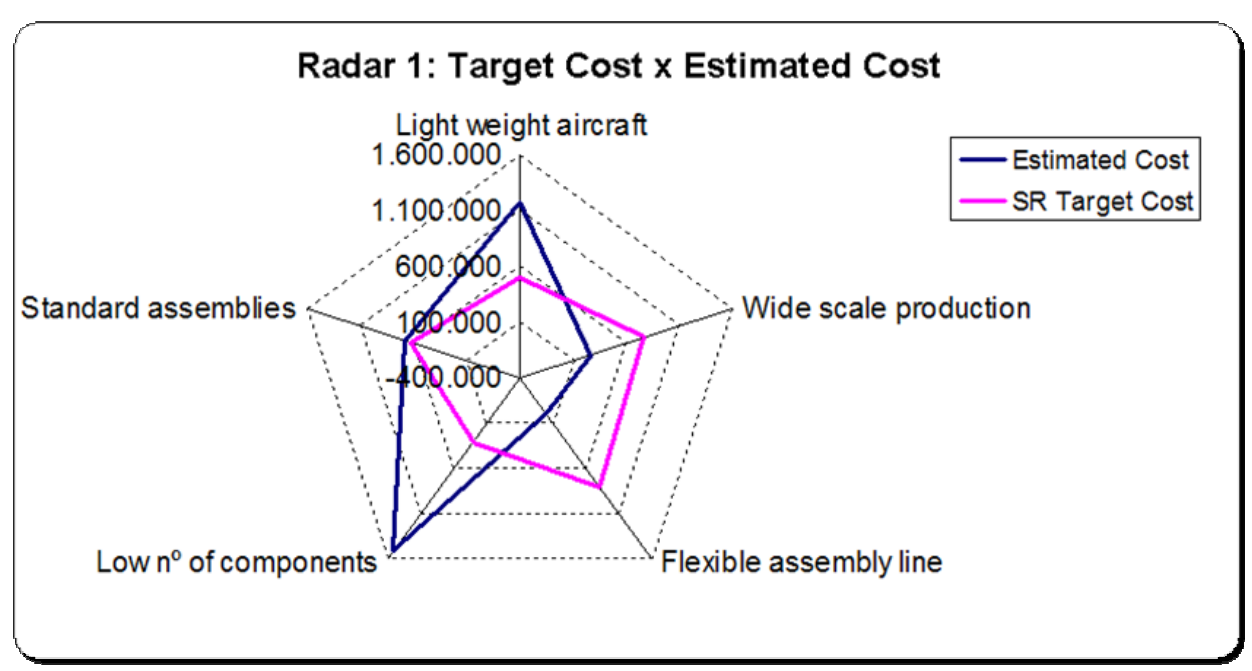

Figure 7 Comparison between the target cost distribution and the estimated cost distribution for design Alternative 2 (see online version for colours)

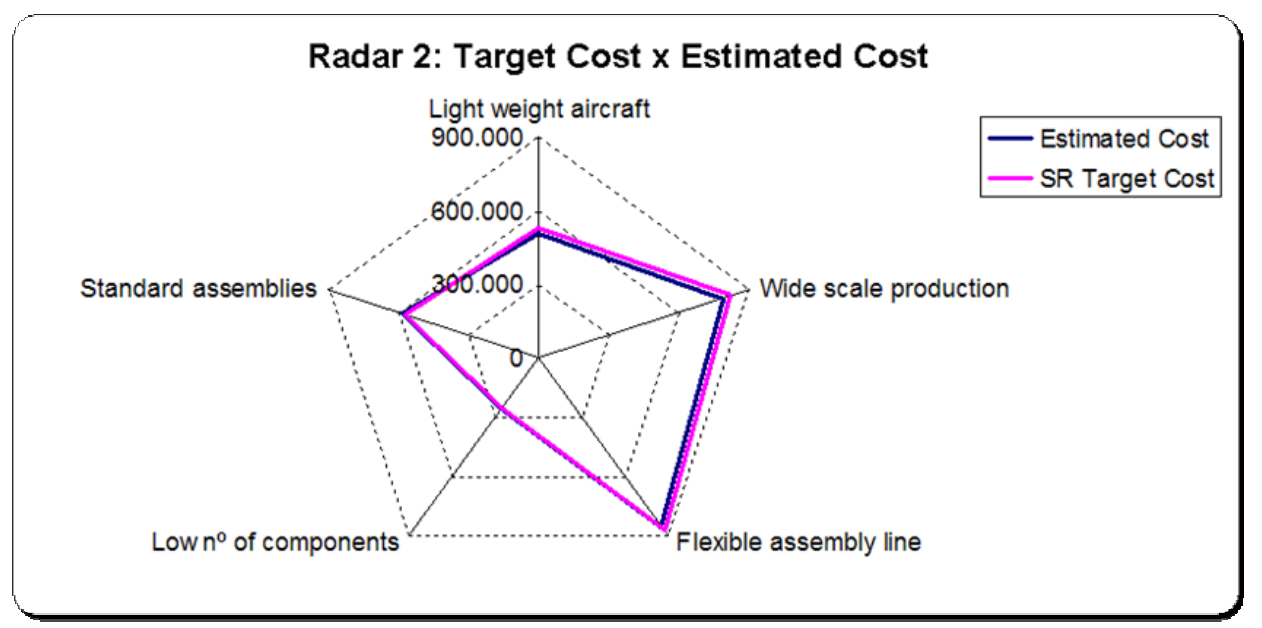

\section{Discussion}

The results of the first and second part of the proposed method can be discussed separately. 


\subsection{Results for the first part of the method}

The planning of the decision making process to implement postponement in an aircraft's production, used DSM (see Figure 3) jointly with the CPM (see Figure 4) techniques to determine the best schedule to make the decisions related to choice of the best product customisation strategy. The schedule of the decisions and questions was done taking into consideration some constraints such as market requirements, product and manufacturing requirements, preliminary supplier data and product maturity.

As the start of the detailed design phase depends on the postponement strategy definition, it is important that the final milestone of postponement strategy definition occurs until the end of the Joint Definition Phase. As can be seen in Figure 4, this constrain was considered.

\subsection{Results for the second part of the method}

By observing the precedence network results for both design alternatives, Alternative 2 presents $1413 \%$ of customisation cycle time reduction if compared with Alternative 1. The major part of this gain is due to the strategic buffers usage for the optional items. However, for Alternative 2, these stocks are feasible just because the hardness and furnishing design was changed and the creation of optional kits after market statistic study. This action contributed to reduce the number of optional items, eliminating those ones with less demand. Then, the stock size was reduced, decreasing the inventory costs to acceptable levels.

The standard hardness design in cockpit and customised in fuselage, for Alternative 2, did not affect the aircraft's weight significantly, because the standard hardness length in cockpit is short, thus the aircraft operational cost was not affected.

The standard cockpit hardness and furnishing design created opportunities to reduce installation times, because the learning curve tends to fall quickly considering that more repeated activities occur.

Alternative 1, although having lower material costs compared with Alternative 2, derived a higher total cost, because the non-conformities costs (non standardised design) and aircraft reconfigurations (high customisation cycle time) contribute to exceed the target cost. Further, observing data in Figure 6, it is possible to notes that the cost distribution is not suitable for Alternative 1, i.e., the systems requirements which have minor importance to customer are presenting higher costs.

Alternative 2 presented not only the lower total cost (1.9\% below the target cost), but its better distribution, associating the higher costs with the most important systems requirements for customer.

These gains consider only one aircraft. So if considering a high monthly production rate, the gains will be in the order of tens of million dollars.

\section{Conclusions}

Comparing the results on Table 11 and Figure 7 with those on Table 9 and Figure 6, it is possible to see the benefits of the design Alternative 2, validating the postponement strategy profit to the company. Through the flexibility increase to meet the demand 
fluctuations of the global market, the reconfigurations costs could be reduced, without losing focus on customer needs.

The final conclusions are that the proposed method met the objectives fully. Through the integration between $\mathrm{CE}$ tools and product customisation concepts, a manufacturing postponement strategy was defined to produce a new aircraft. The DSM was a very practical tool to establish the relationships among the questions and decisions to be made in order to decide which customisation strategy will be adopted, simplifying the use of CPM to create the decision process plan. The jointly use of QFD and DTC posed itself a good solution to determine the best design alternative, because it was possible to consider not only the cost point of view, but also the customer value point of view.

\section{References}

Ame Info. (2004) Manufacturing Postponement Strategies Come of Age, available at http://www.ameinfo.com/40996.html (accessed on 8 October 2005).

Aviv, Y. and Federgruen, A. (2001) 'Design for postponement: a comprehensive characterization of its benefits under unknown demand distributions', Operations Research, Vol. 49, No. 4, pp.578-598.

Beckman, O.R. and Neto, P.L.O.C. (2000) Análise Estatística da Decisão, Edgard Blücher, São Paulo, SP.

Bullock, P.J. (2002) 'Knowing when to use postponement', International Logistics, available at http://www.its.usyd.edu.au/past_assignments/tptm6260_bullock_2002.pdf (accessed on 10 September 2005).

Cunha, D.C. (2002) 'Avaliação dos resultados da aplicação de postponement em uma grande malharia e confecção de Santa Catarina', 174 p., PhD thesis, UFSC, Florianópolis.

Darci, P. (2004) PERT/CPM, INDG, São Paulo, SP.

Graman, G.A. (2002) 'A numerical analysis of capacitated postponement', Production and Operations Management, Michael J. Magazine, Dayton, Vol. 11, No. 3, pp.340-357.

Hoffmeister, A.D. (2003) 'Sistematização do processo de planejamento de projetos: Definição e seqüenciamento das atividades para o desenvolvimento de produtos industriais', 135 p., $\mathrm{PhD}$ thesis, UFSC, Florianópolis.

Iyer, A.V., Deshpande, V. and Wu, Z. (2003) 'A postponement model for demand management', Management Science, Vol. 49, No. 8, pp.983-1002.

Lee, G.H. and Kusiak, A. (2001) 'The house of quality for design rule priority', The International Journal of Advanced Manufacturing Technology, Vol. 17, pp.288-296.

Lembke, R.S.T. and Bassok, Y. (2004) 'An inventory model for delayed customization: a hybrid approach', European Journal of Operational Research, Los Angeles, Vol. 165, pp.748-764.

Ma, S., Wang, W. and Liu, L. (2002) 'Commonality and postponement in multistage assembly', European Journal of Operational Research, Vol. 142, pp.523-538.

Michaels, J.V. and Wood, W.P. (1989) Design to Cost, Wiley-Interscience John Wiley \& Sons, Canada.

MIT and UIUC DSM Research Teams (2003) The Design Structure Matrix - DSM Home Page', available at http://www.dsmweb.org/ (accessed on 17 December 2005).

NASA (2005) Presentation on Training for the Use of Dsm for Scheduling Questions, Decisions and Milestones for the Definition of Roadmaps, Washington DC.

Peralta, A.C. (2002) 'Um modelo do processo de projeto de edificações, baseado na engenharia simultânea, em empresas construtoras incorporadoras de pequeno porte', 143 p., $\mathrm{PhD}$ thesis, UFSC, Florianópolis. 
Peralta, A.C. and Tubino, D.F. (2003) O uso do DSM no processo de projeto de edificações, available at http://www.eesc.sc.usp.br/sap/projetar/files/A018.pdf (accessed on 18 December 2005).

Pinedo, M. (2002) Scheduling - Theory, Algorithms, and Systems, Prentice Hall, New Jersey.

Prats, L. and Patterson, J. (2003) New Supply Chain Study Finds Postponement Strategies Critical for Reducing Demand Uncertainty and Improving Customer Satisfaction, available at http://www.oracle.com/corporate/press/2436365.html (accessed on 14 August 2005).

Primavera Project Planner (1997) User Manual-version 2.0b, Primavera Systems Inc.

Raiffa, H. (1970) Decision Analysis - Introductory Lectures on Choices under Uncertainty, Addison Wesley, USA.

Sampaio, M., Duarte, A.L.C.M. and Csillag, J.M. (2003) 'O poder estratégico do postponement', 3rd International Conference of the Iberoamerican Academy of Management, available at http://www.fgvsp.br/iberoamerican/Papers/0304_ACF55A.pdf (accessed on 8 August 2005).

SM Thacker and Associates (2000) Postponement and Mass Customization, available at http://www.smthacker.co.uk/postponement_mass_customisation.htm (accessed on 25 September 2005).

Souza, C.E. (2000) Primavera Project Planner - Guia de aprendizado básico versão 3.0, Verano Engenharia de sistemas.

Tseng, M. and Jiao, J. (1998) 'Concurrent design for mass customization', Business Process Management Journal, Vol. 4, No. 1, pp.10-24.

Vitaliano, W.J. (1994) 'Three design to cost myths', International Conference of the Society of American Value Engineering, New Orleans, LA.

Waller, M.A., Dabholkar, P.A. and Gentry, J.J. (2000) 'Postponement, product customization, and market-oriented supply chain management', Journal of Business Logistics, available at http://www.findarticles.com/p/articles/mi_qa3705/is_200001/ai_n8889247 (accessed on 14 September 2005). 